\title{
EVALUATION OF THE WORK PROGRAM IMPLEMENTATION OF THE STRATEGIC PLAN SENIOR HIGH SCHOOL OF STATE 28 KAB TANGERANG
}

\author{
SupiHidayati $^{1^{*}}$ AgusIwan Mulyanto $^{2^{* *}}$ Anggih Perian GP $^{3 * *}$ \\ ${ }^{123}$ Universitas Islam S yekh-Yusuf, Tangerang \\ *)supi.hdyti@gmail.com *)ai_mulyanto@unis.ac.id ***)anggih.pgp@gmail.com
}

\begin{abstract}
This research is evaluating the Strategic Plan work program at Senior High School. Observational methods use CIPP (Context, Input, Process, Product) models by Stufflebeam\&Shinkfield. This program is one type of object of evaluation research (Evaluation Research). The fundamental orientation in all evaluation research is benefits. The strategic plan for implementing the Senior High School program needs to mark improvements related to the MIA and IIS Study Programs. Suggested observations of implementers Strategic Plan followed up on many findings, especially those concerning the program, and make improvements to the program so that the Strategic Plan program process activities become more effective.
\end{abstract}

Keywords: Strategic Plan, Work Program Evaluation.

\section{A. Preliminary}

Article 31 paragraph 1 of the 1945 Constitution Article 1, which reads: "Every citizen has the right to be taught" for that the state has responsibility for education by requiring every citizen to get a proper education, to answer the appropriate educational needs. Act no. 20 of 2003 concerning Education, as a legal umbrella where formal or informal schools need to translate what constitutes the basis of the constitution to reconstruct, reposition and replan preparing students to have reliable performance and human resources who have characters who are able to win global competition as listed in public school education that is managed professionally is an answer in meeting needs. Act no. 14/2005 related to Teachers and Lecturers, has a goal to be able to develop the world of education towards the competency of international standard high schools that have fields of study with existing budget plans, must be able to design schools that are in the future to compete in line with the ideals of $\mathrm{Ki}$
Hajar Dewantara (Father of National Education Indonesia) which explains the importance of education, "which is generally the effort to advance character (character, inner strength, mind intellect) with nature and society". The implementation of strategic planning always strives to be the best thing. Through this global-minded school, it is hoped that the development of a global-minded school can be realized through the preparation of strategic planning as an implication of a decision.

In the midst of the chaos of the 2013 curriculum that developed and the complexity of the education system, the implementation through the work plan was a strategic plan. The Ministry of Education and Culture in 2015-2019 was prepared based on Act No. 17/2007 concerning the 2005-2025 National Long-Term Development Plan, Act No. 20 of 2003 concerning the National Education System, Law No. 25/2004 concerning the National Development Planning System, Presidential Regulation No. 5/2010 concerning the 
National Medium Term Development Plan 2010-2014. This strategic plan of the Ministry of Education and culture is regulated in the Ministry of Education and Culture Regulation No. 12/2018 whose implementation is still implemented and implemented.

"Strategic Planning is a management tool used to manage current conditions to project conditions in the future, so the strategic plan is a guide that organizations can use from the current conditions for them to work towards the next 5 to 10 years" Kerzner (TT). Furthermore "strategic planning is the process of deciding which programs will be carried out by the organization and estimates of the number of resources that will be allocated to each program over the next several years" Robert N. Anthony (TT). To achieve a strategy that has been determined by the organization in order to have a competitive advantage, the company leaders, operations managers, must work in a system that is in the strategic planning process. Manufacturing capabilities must be used appropriately so that it can be a superior weapon in strategic planning. "Strategic planning is explicitly related to change management, this has been the result of research by several experts" (e.g., Ansoff, 1965; Anthony, 1965; Lorange, 1980; Steiner, 1979). Also "activities that include a series of processes from innovation and change the company, so that if the strategic planning does not support innovation and change, then that is a failure" Lorange (1980).

"Evaluation is the process of systematically collecting and analyzing information in order to form value judgments based on firm evidence." Rogers (2005:2). This assessment looks at the extent of its achievement so that a decision is made, so that appropriate data collection is carried out as a basis for assessment, then. "Evaluation is a systematic investigation of the merit or object of reducing uncertainty in decision making about the object" Mertens (2004:17).

The program as a unit of activity which is the implementation of policy takes place in a continuous process, and an organization takes place involving a group of people. The program "is connected with all other aspects (goals, context, participants, needs, staff, materials, outcomes), it is essential that evaluation programs focus on issues that are the effective and manageable design that will be implemented and will attract necessary resources and cooperation "Knox (2002: 201). So the program is something that someone or institution does in the hope that it will bring results or influence.

\section{B. Method}

This program evaluation study uses a descriptive method with the Context, Input, Process, Product (CIPP) model developed by Stufflebeam\&Shinkfield and "the research approach is the overall activities carried out in carrying out research starting from formulating the problem to conclusions" (Purwanto, 2008:45). The approach of this research is a qualitative approach, "... called qualitative because the data collected and the analysis are more qualitative" Sugiyono (2013:14). Program evaluation is evaluation research whose basic orientation in all evaluation research is the benefit of providing information to make decisions in the framework of improving services that are implemented and evaluated for the 20152019 period.

\section{Discussion}

The steps to formulate a school strategic plan are the basic foundation for the importance of making a strategic plan at the school. Strategic plans are made from the results of school evaluations by looking at eight education standards: 1. Graduate competency standards, 2. Content standards, 3. Process standards, 4. Education standards and education personnel, 5. Standard of facilities and infrastructure, 6. Management 
standards, 7 Education funding standards and 8. Education assessment standards Act no. 19 of 2005 as outlined in Minister of Education and Culture Regulation No. 24 of 2016. Of the eight standards set by the government, it knows its superiority and weaknesses in its field, then develops, the part that has been well maintained must even increase the still weak we increase/improve its quality in order to be better and fulfill the requirements, so that from the eight education standards set by the government of the school can meet education quality standards even better if they can exceed the standards set by the government. When the President gave a statement to revitalize schools, especially in the field of human resources to have competitiveness at the global level in the labor market, then schools certainly through eight education standards immediately made improvements and focused on government goals, so that they could align and support all government programs. The main issue of the school is always following the developments that occur and of course always talking through school work meetings, which usually when the meeting begins with the results of early school evaluations besides the teachers also see the results of monitoring evaluations conducted by the education office from the results taken points, fields what needs to be recommended to be issued or replaced. Schools always do the best in order to produce human resources that are truly able to meet the needs of using demand ever principles, preparing graduates who are able to compete in the community, or in the choice of courses that are the favorite of students by printing human resources. By printing graduates based on the needs of the community and universities, the innovation of the school opens up new competencies so that later they will have the opportunity to open up the competencies of other study programs in addition to the two study programs.
The formulation and drafting steps are carried out by the formation of a committee established through schoolwork meetings from the committee. The responsible fields are formed including: graduate competency standard fields, standard content fields, education standard fields, infrastructure standard fields and standard funding fields, each of these fields later it will arrange the plan according to the work program and the results of the evaluation of the strategic plan and at the end of the work meeting session each commission or field presents the results of the deliberations in each field then after everything is explained then it will be done in general-together then formulated into evaluation plans strategic. The level of suitability of the contents of the document The school's strategic plan must be in accordance with the vision and mission that have been set. Developing a strategic plan to align with the vision of the school must involve all elements in the school by involving elements of the school organizational structure starting from the deputy head of the curriculum in the fields of industry and community relations, student affairs, education facilities and infrastructure, then assisted by the head majors, each of the department heads is the same in seeing the results of school performance evaluations. By looking at the previous school program plan and next year's school program plan, all of that will be arranged together so that it can become a superior program so that it can manifest from the school's vision. Developing a strategic plan to be aligned with the mission of the mission school is a derivative of more vision on the long-term achievements to be realized must be reduced to the mission of the school.

The mission is how to make the program be able to realize the dream of the school whether it can be achieved. So vision in rent must be broken down into a mission, the mission of the institution is broken down 
into each expertise competency, then from each mission both institutional or competency expertise in the breakdown is a real activity that can be implemented and all of it is planned and monitored later through a program. The implementation of the strategic plan to date has always been going well but on that trip there has always been a slight change, this happens because sometimes there are sudden programs that must be carried out in the midst of unplanned activities but it must be carried out like those recommendations when evaluated, it turns out that there are activities that are not included in the program plan but that additional programs must be implemented. The program is an insertion or sometimes impromptu but is still handled so that it can be a record for the high school, especially so that there is an appointment on the next strategic plan so that it is planned to be better so that such things can be minimized to occur. Increasing relationships with other communities and institutions/government institutions is continuously improved by making certain memoranda of understanding so that they feel comfortable and satisfied with what has been done to improve their status into a tangible form of cooperation with those that have to do with social problems, involving the students whose implementation is directly placed at school.

There is a chance to practice when the school makes the students of Senior High School graduate become quality. The alumni formed an association of alumni ties through each alumni activity to find out the careers of their graduates. Indeed, there have not been any officials in the private company and even the owner of the owner because the school has only been running for 9 years, but there are graduates who have been able and managed to establish a private business, with this opportunity to make the community and the environment benefits, there are even certain departments whose graduates have been recruited by alumni schools. How is the strategic plan implemented and evaluated? Evaluation carried out to determine the success rate of the strategic plan is by evaluating each of the agendas existing in the previous strategic plan, evaluation based on the school self evaluation instrument where each evaluation indicator has a standard indicator or using instruments in monitoring evaluation in which there are also standards that assess whether the performance has met the target of the strategic plan or even exceeds the target. Looking at the indicators, they can find out their position and how far they can be drawn from the spider-web nest from the school's self-evaluation results.

The evaluation period carried out through the first types of evaluations is directly or directly evaluating the implementation carried out quietly by finding individuals to be supervised, but those who have been programmed are semester supervision, in one semester minimum supervision is carried out twice in the middle semester and end of semester, so in one year the planned supervision will be carried out four times. Auditor supervision activities are continuing and until now these activities have gone well for example of supervision at Senior High School, namely, when teachers teach, the team of supervisors conducts an assessment. We form this supervisor on the principal's decision and then appoint the team of supervisors with the issuance of a decision letter as the supervisor in the decree which also states who will be supervised. The results of supervision will be given to supervised teachers, the school will discuss with the individual concerned and find a solution if there are some weaknesses or mistakes made by the teacher, this is done to improve the quality of the teachers to be more qualified and professional. Schools make school management with a business-based approach.

Such an approach is always carried out, in the process of implementation, the 
responsible supervision of the teacher when the teachers and the team run the principal's program assisted by the ranks which have been crossaudited at Senior High School is called the term internal audit. This internal audit has a rule that the person conducting the audit is not the person in the group. For example checking the curriculum, it is done by bit people or vice versa bit people will also be audited by the people to become accountable, must walk with the supervision of attachments, increase interest in becoming students who can be accepted in all universities, both public and private and how learners are taught to have high self-esteem, foster persistence, be resilient in living it, not easy to give up or despair, and can create opportunities or be clever to take advantage of the most important opportunities for these students that are able to implement what being the ability to be soft and hard competent so capable students are also invited to be able to work from their ideas either directly or indirectly. The direct intention is that students can practice directly or get involved in their fields. Meanwhile, the purpose of it is indirectly through observation of the results of training conducted by the community related to the fields of expertise chosen by students. Improving mono track learning means scheduled and monitored implementation is supported by picket teachers in the implementation towards the end of the semester, be it a national exam or a school exam implementing reinforcementstrengthening programs for students through directing and testing tests that do intensely programmed and continuous. The way the school also looks at the success of the students is by measuring two aspects, namely the academic and non-academic aspects.

Academic aspects can be seen from the results of national examinations and two other exam results that are characteristic of vocational schools, namely the skills competency test and vocational theory exam coupled with general examinations as well as the standard examinations in schools. Then this non-academic aspect can be achieved through various activities that exist in school extracurricular activities. For example, competency competitions for sports students, sending students in competitions at the city, provincial or national level, including futsal, taekwondo, and pencaksilat, etc. The number of achievements obtained is the result of development in the evaluation of strategic plans shaded by student activities so that students can carry out activities in accordance with plans on strategic plans, Senior High School focuses so that students can achieve achievements and become successful individuals in academic and nonacademic fields.

\section{Conclusion}

Based on the discussion in the previous chapter, results were obtained about internal and external strengths and weaknesses, the main issues and the formulation steps as well as the preparation of strategic plans, the suitability of the contents of the strategic plan documents with the vision, the defined mission, the implementation of the 2015-2019 period. Then it can be concluded as follows:1) The strengths and weaknesses of internal and external strategic plans can be concluded that the strength of Senior High School is very good because it has quality human resources, complete facilities and infrastructure, good social capital and the realization of good cooperation with the private sector and government in absorbing graduates. As for the weaknesses, namely the continued development of technology and information so schools must continue to update the material and learning methods and tools of machine practice.2) The main issues and steps of formulation and preparation of strategic plans, the main issues by looking at the needs of the labor market so schools will continue to be innovated to open new competencies. The 
formulation and formulation of a strategic plan is carried out by forming a committee established through school work meetings from the committee formed by the responsible fields including: graduate competency standard fields, standard content fields, education standard fields, infrastructure standard fields and standard funding fields, each field The later will arrange the plan according to the work program and the results of the evaluation of the previous strategic plan and at the end of each work meeting the fields present their findings and then formulate them into the next strategic plan.3) Conformity of the contents of the strategic plan document with the vision, the mission that has been set, the program is made by looking at the results of previous program evaluations involving all elements in the school, namely the principal, deputy principal in the curriculum, community relations, student affairs, facilities, and infrastructure. The results of the coordination are excellent programs that can realize the vision and mission of Senior High School. 4). Implementation and evaluation of strategic plans, evaluation is carried out by looking at the previous strategic plan based on the school selfevaluation instrument where each evaluation has a standard indicator that is reflected in the cobwebs of the evaluation results. The planned evaluation period is conducted four times a year carried out in the middle of the semester and the end of the semester as well as the type of evaluation directly or direct evaluation and semester supervision. Supervisors are formed on the decision of the principal by issuing a decision letter as the supervisor. The results of the supervision are presented to supervised teachers, the school makes improvements to the teacher concerned and looks for solutions so that the teacher becomes more qualified and professional. Teacher recommendations are the spearhead of the success of education and are considered as people who play an important role in achieving educational goals which are a reflection of the quality of education. The existence of teachers in carrying out their duties and obligations cannot be separated from internal influences or external factors that have an impact on changes in teacher performance. Teacher performance is the ability that the teacher shows in carrying out his duties. Performance can be said to be good and satisfying if the objectives achieved are in accordance with established standards. In achieving good quality education is strongly influenced by the performance of teachers in carrying out their duties so that teacher performance becomes an important demand for achieving educational success. As described above the results of teacher performance evaluations, there are several obstacles that can hamper teacher performance in carrying out their duties, so corrective actions should be taken to improve teacher performance.

Corrective actions that can be carried out are a) The school principal regularly monitors the teacher. Can provide supervision in helping teachers manage learning hours in class. The teacher can also make different lesson plans with different methods according to the conditions of the class. The principal can provide encouragement to the teacher to free up the methods used in managing the sons and daughters' classes. Because the atmosphere and conditions of different classes should use different methods so that students can receive the subject matter well. b) Principals, teachers, employees, guardians of students and the community should work together in the development of education. So, the involvement of all parties also helps in improving teacher performance. Guardians of students can communicate well with teachers about the development of students in school. Stakeholder communication in schools is one way to improve the quality of education, schools can communicate activities, programs, and funding related to student learning. so that after graduating students can get good personal values. c). 
Less teacher discipline will result in disruption of the teaching and learning process due to the ineffectiveness of learning hours. So, the principal must take firm action to reduce this. With the absence of teachers every day, if it is late or does not come during the learning process is not clear. Then the headmaster or the authorized leader can give a warning or dismissal of the teacher concerned. In addition, it is necessary to motivate teachers to work in school also needed to improve teacher performance. A diligent teacher, a teacher who is valued well in carrying out his duties should be given appreciation. This is intended to encourage teachers to carry out their duties at school and provide the best for the development of students. d). The process of recruiting teachers who must comply with standards. One of the competent teachers in their field, namely the recruitment of teachers is done by using appropriate tests. In an effort to improve the quality of education several things can be done that can affect teacher performance so that more leverage is as follows:1). Carrying out the Subject Teachers' Consultation program is a forum for professional activities of similar subject teachers, which are expected by teachers to improve learning methods, technical education about science and technology that can be used in classroom learning, information sharing, and increasing teacher professionalism. 2). Empowerment of teachers in schools. Teacher empowerment can be done with an integrated competency-based training program. This can encourage teacher performance to increase so that learning outcomes by students are also good. The training needed is training that is tailored to the needs of the teacher, namely training that refers to the demands of teacher competence. This training can be held independently by schools, or government programs. Teachers must increase their competence, increase knowledge and sources of learning that will have an impact on improving the quality of education for students.

\section{Bibliography}

Glyn Rogers and Linda Badham, Evaluation in schools (2005): Getting Started On Training And Implementation. New York: Routledge,

Donna M. Mertens, John A. McLaughlin (2004). Research and evaluation methods in special education. California: Corwin Press, Inc.

Alan B. Knox (2002). Evaluation for continuing education: a comprehensive guide to success. Denver: John Wiley \& Sons, Inc.,

Daniel L Stuffebeam and Anthony J. Shinkfield, (1995): Teacher evaluation: Guide to Effective Practice. Boston: Kluwer Academic Publishers,

Daniel L. Stufflebeam (2001), Evaluation Models, Viewpoints on Educational and Human Services Evaluation Second Edition. Boston: Kluwer Academic Publishers,

Daniel Wallach et.al. (2006), Crop with Dynamic Models Evaluation, Analysis, Parameterization, and Applications. Amsterdam: Elsevier B.V.

David Royse et al. (2010), Evaluation Program. Belmont: Wadsworth Cengage Learning,

Lexy J. Moleong (2002), Qualitative Research Methods (Bandung Youth Rosdakanya.

Nasution (2003), Qualitative Naturalistic Research Method, third reprint of Bandung: PT. Tarsito,

Peter H. Rossi et al (1999), Evaluation A Systematic Approach. California, SAGE Publications, Inc., 
Rachmat (2013), Strategic Management. Bandung, Faithful Library,

Richard Kiely and Pauline Rea Dickins (2005), Evaluation Program in Language Education. New York: Palgrave Macmillan,

Siri N. Espy (1986), Handbook of strategic planning for nonprofit organizations. New York: Praeger Publishers.

SMAN 28 Kab. Tangerang, 2015 Strategic Plan -2019, not published. 